\title{
MASTODONS (Mammut americanum) AND THE LATE-GLACIAL VEGETATION OF THE EASTERN USA
}

UMD

DRAZAN, Jacqueline L. ${ }^{1}$, MOOERS, Howard D. ${ }^{1}$, MOEN, Ron ${ }^{2}$, PASTOR, John ${ }^{2}$, LARSON, Phillip ${ }^{1}$, SWARTZ, Jennifer A. ${ }^{1}$, DAVID, Mady K. ${ }^{1}$, BOPRAY, Croix K. ${ }^{1}$, JAKSA, Michael P. ${ }^{1}$ and MESSER, Blake S. ${ }^{1}$,

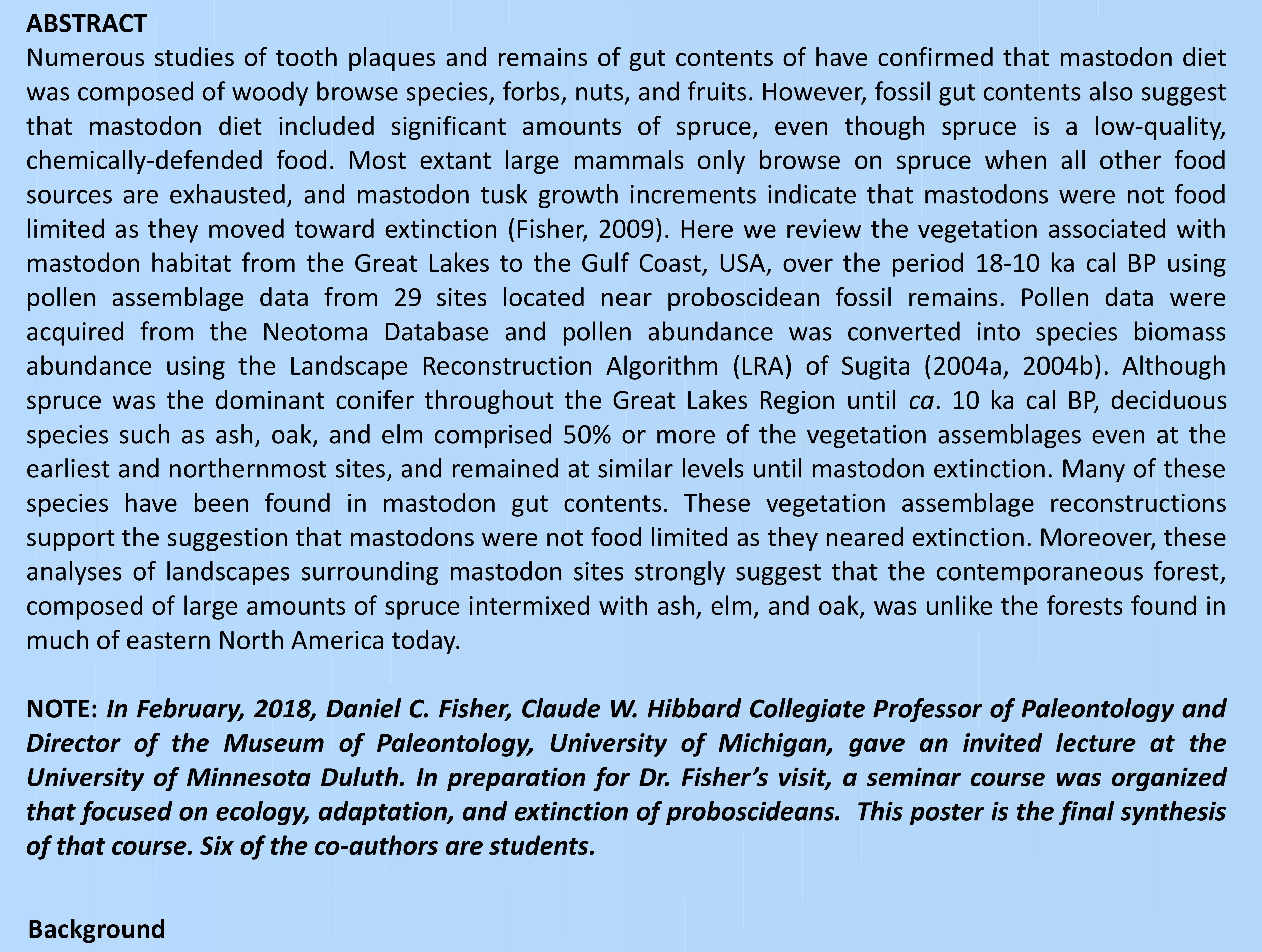

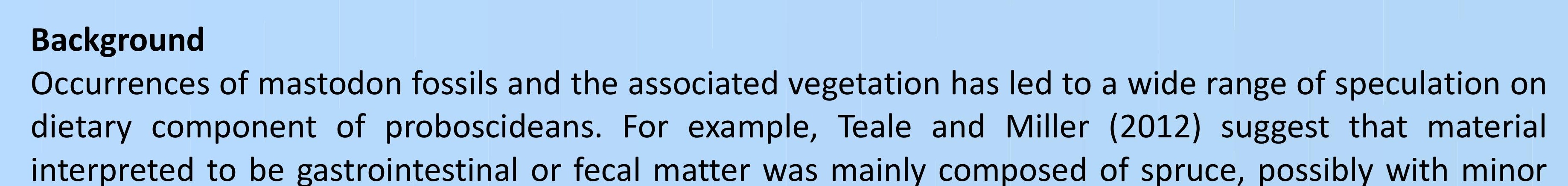

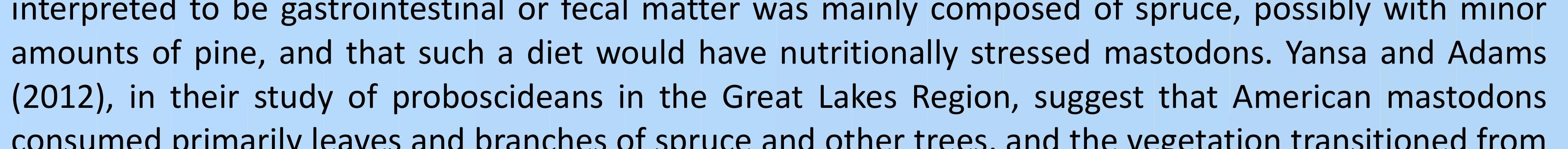

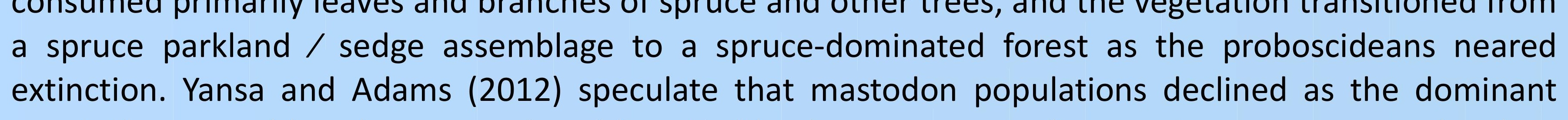

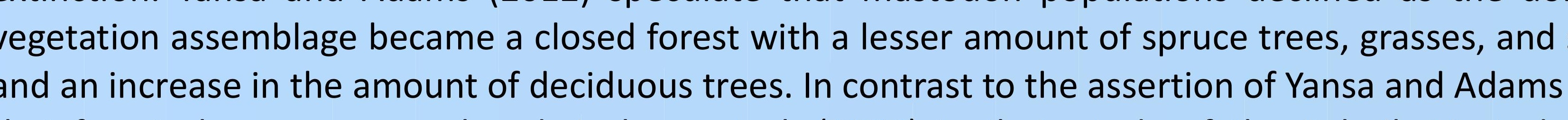

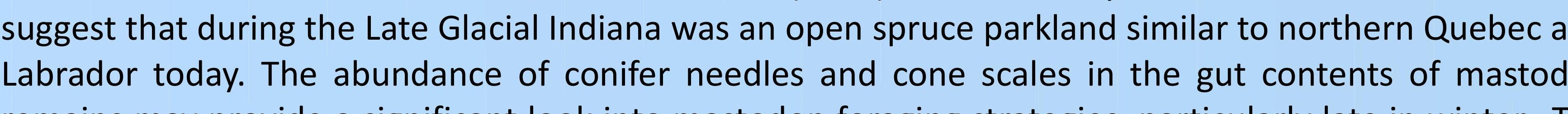

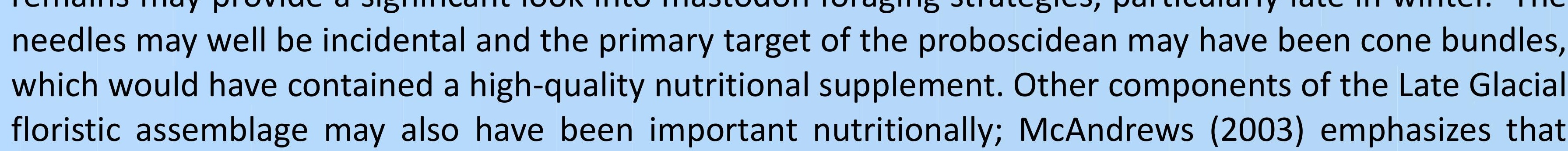

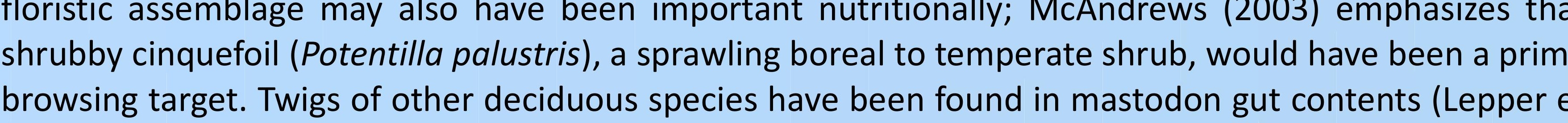

Methods
To examine

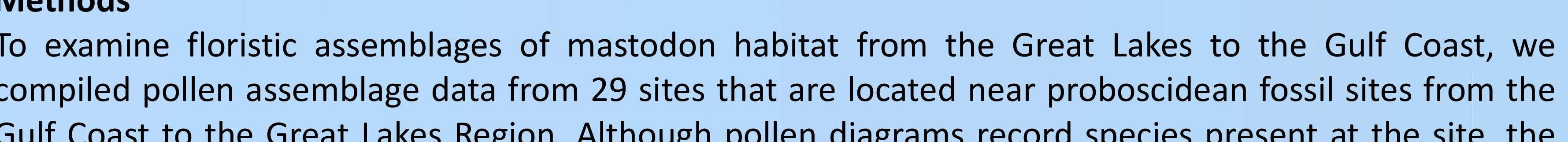

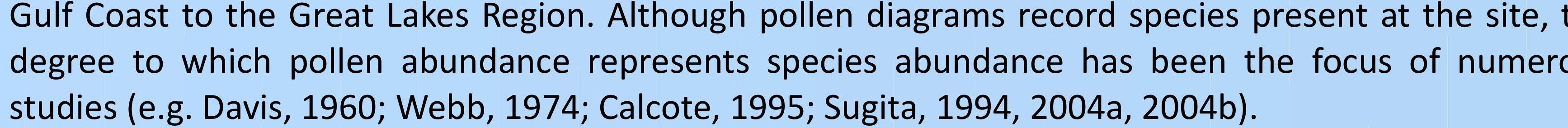

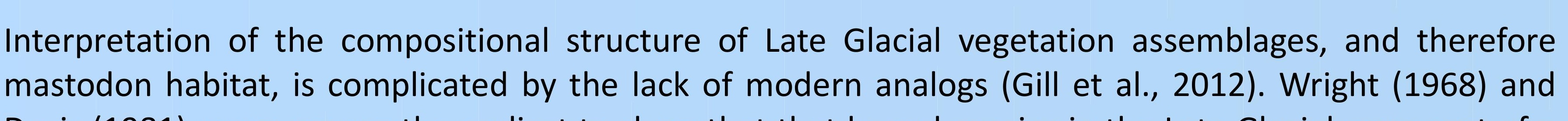

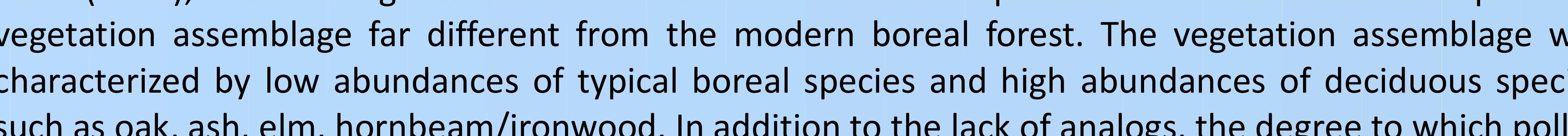

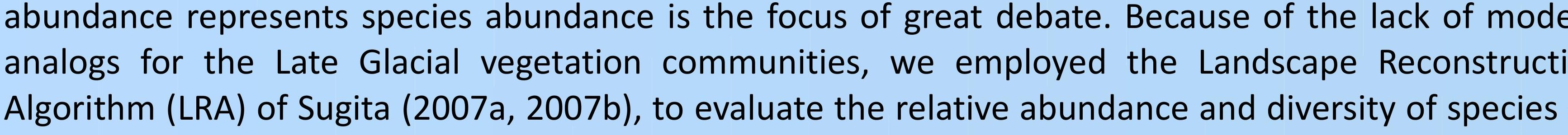

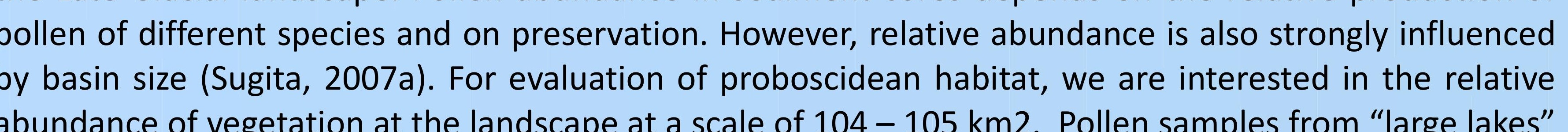

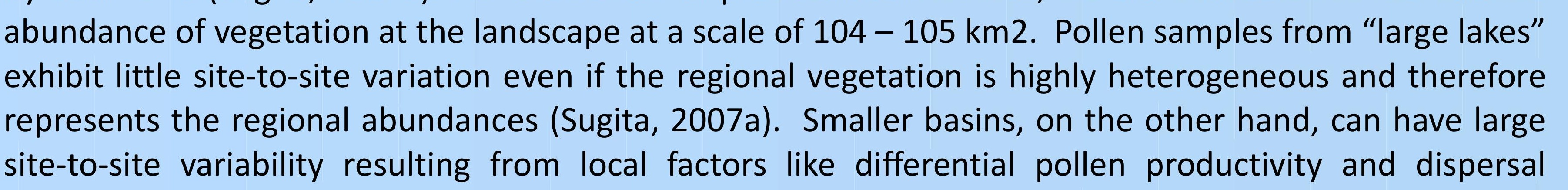

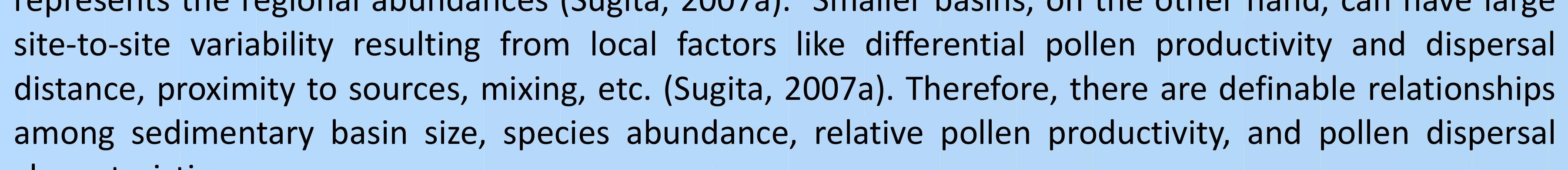

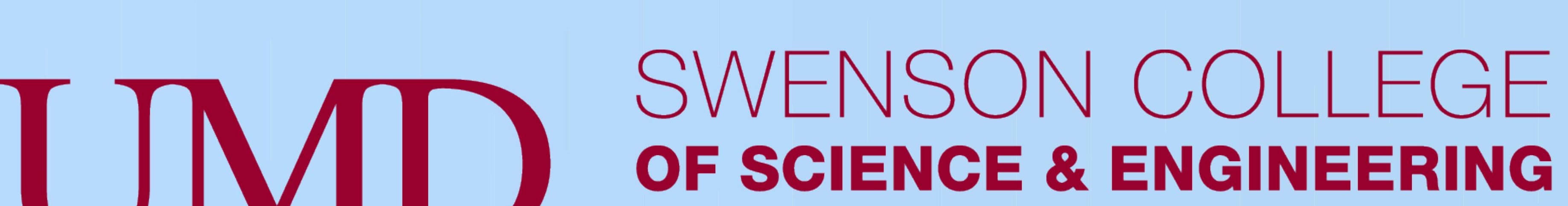

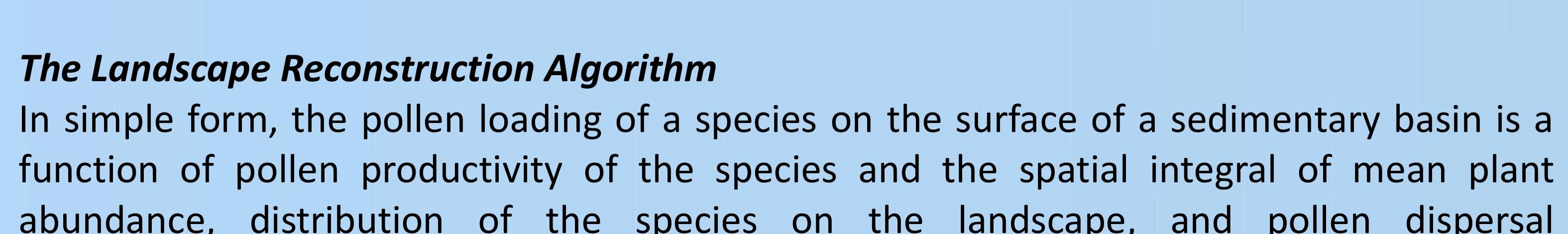

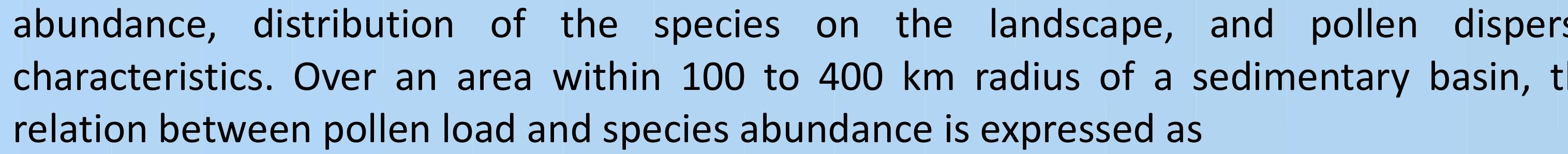
$y_{i k}=P_{i} \int_{R}^{2} \bar{X}_{i} \cdot g_{i}(z) \cdot \mathrm{d} z$

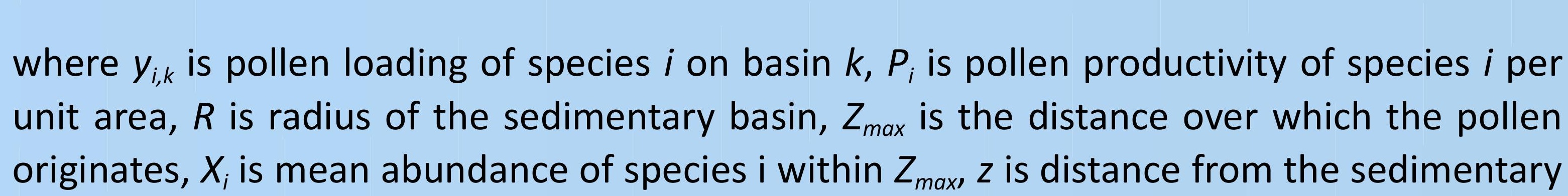

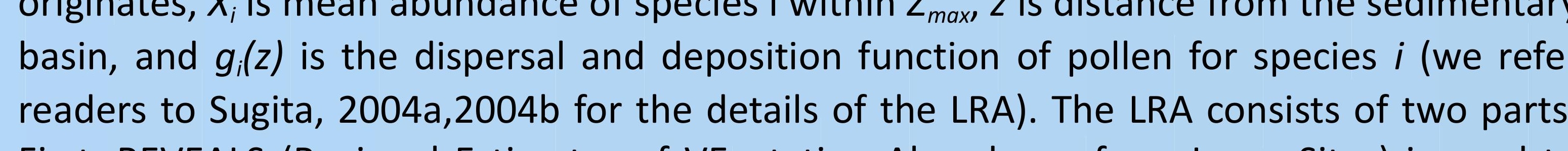

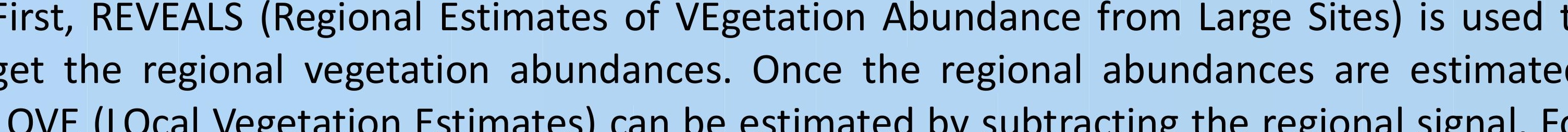

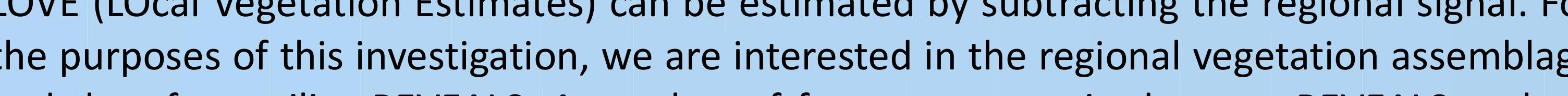

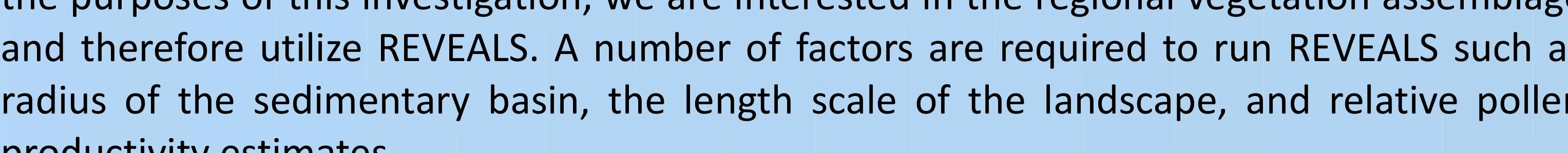

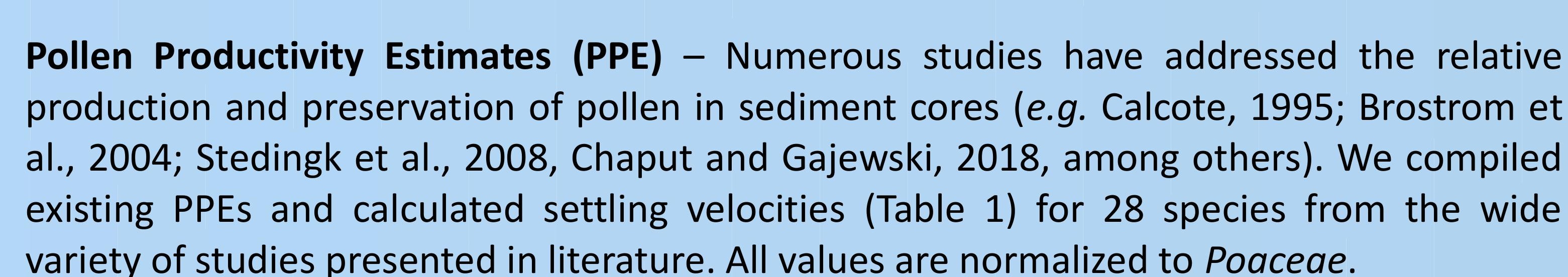

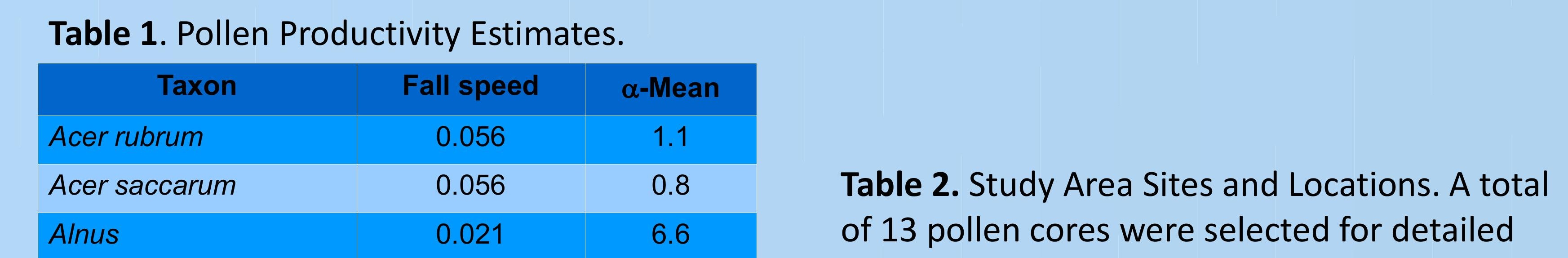
Table 2 . Study Area sites and Locotions. A total
of 13 pollen cores were selected for detalied

西

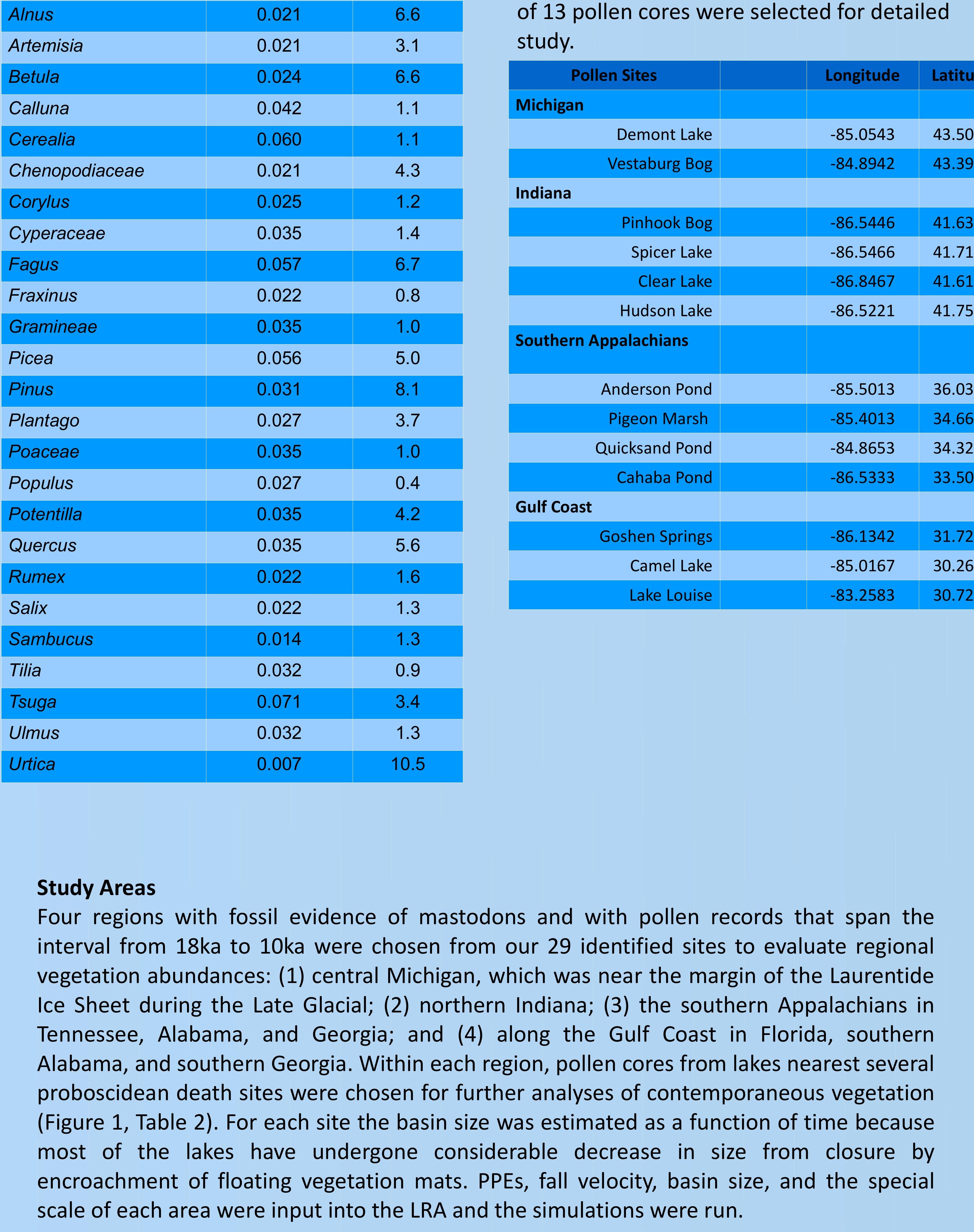

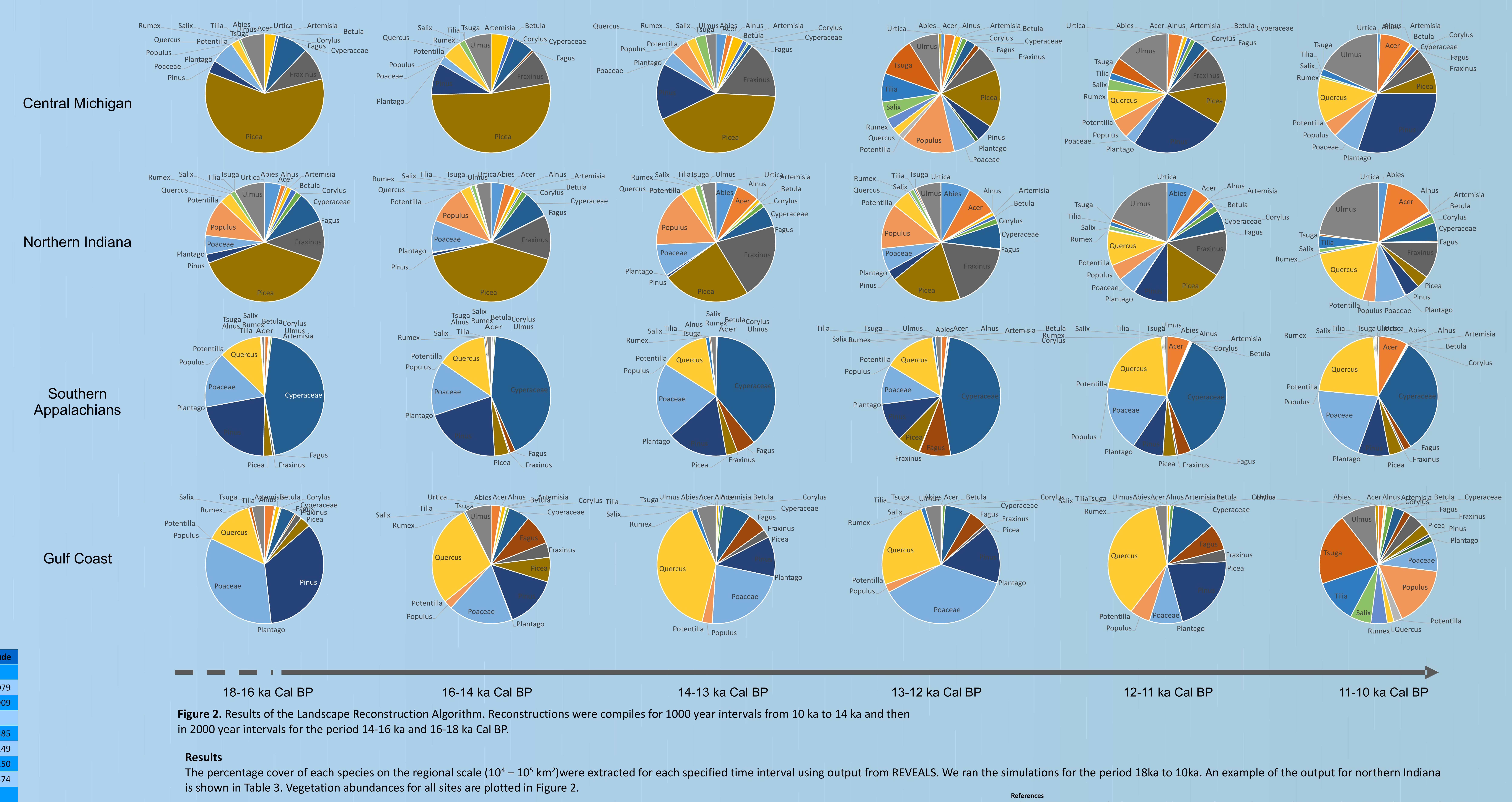

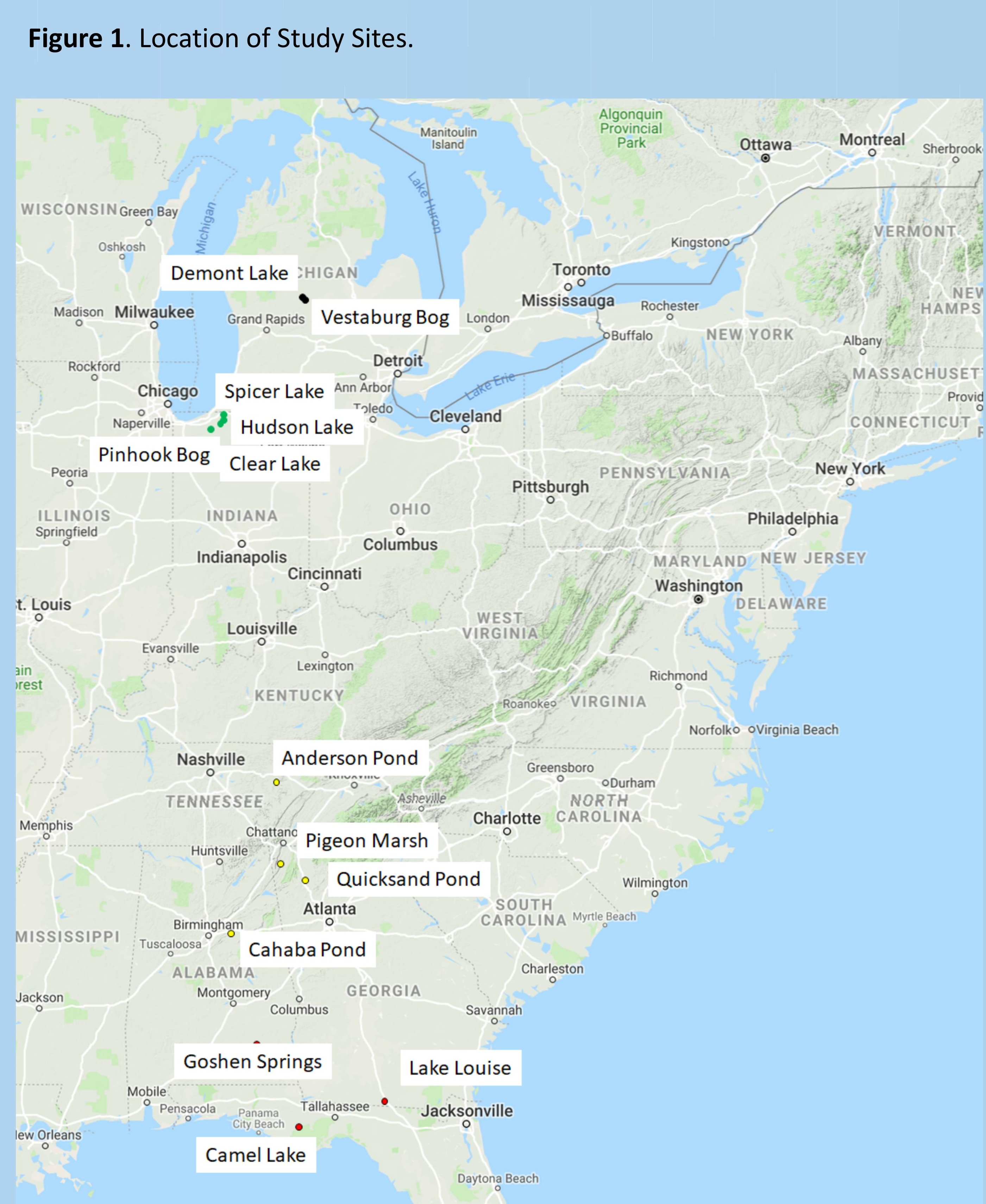

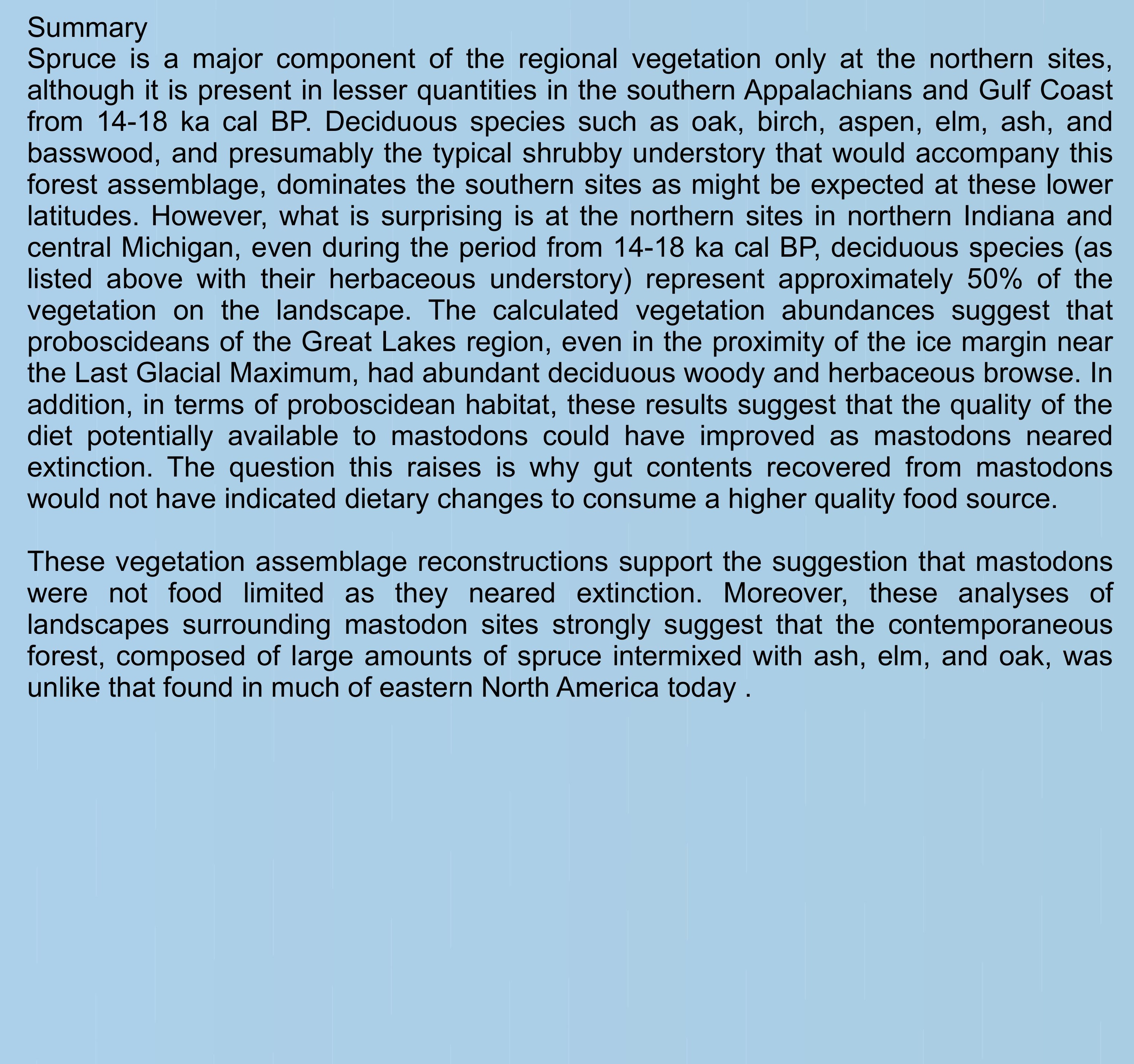

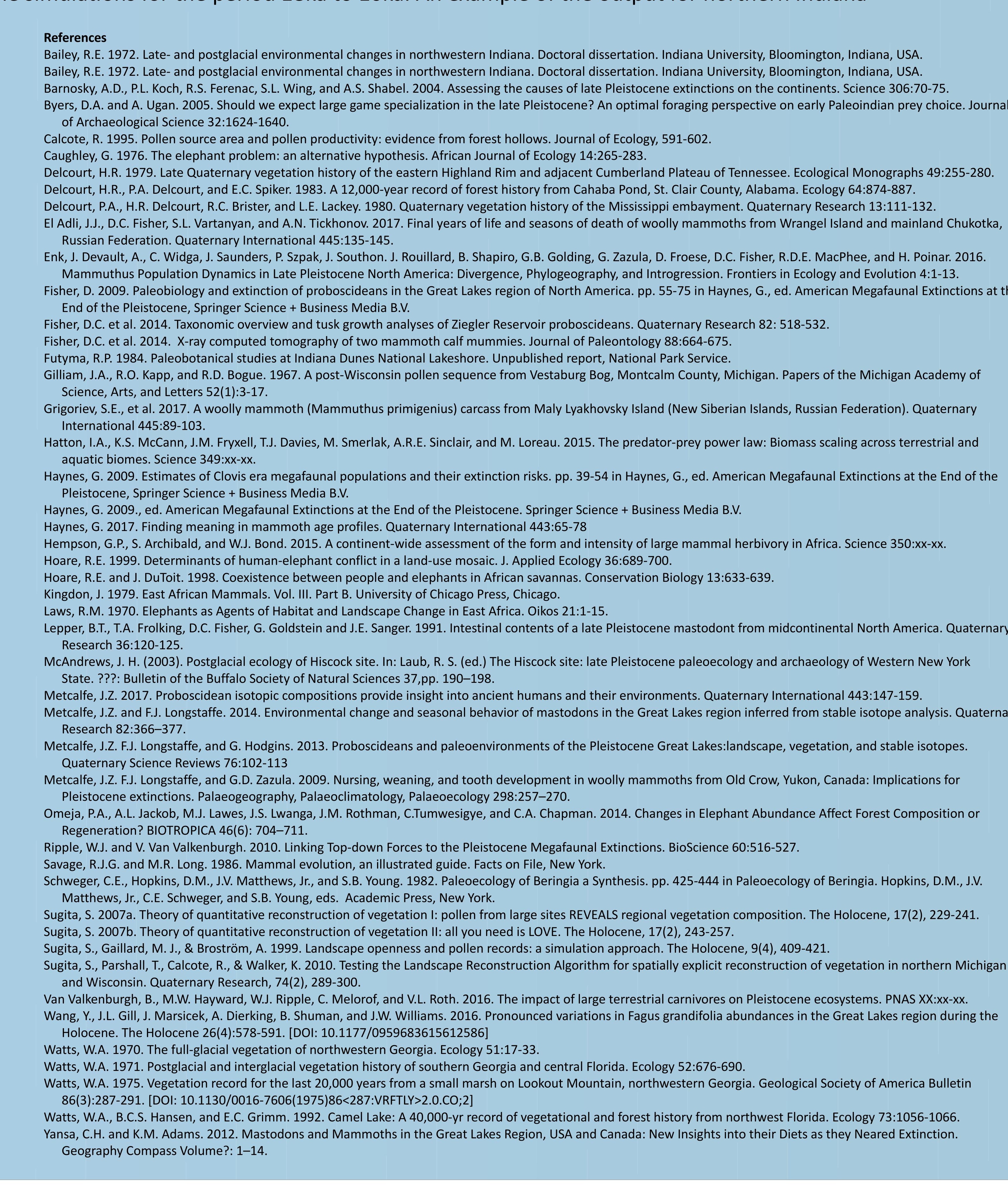

